\title{
An integrated approach for solving a MCDM problem, combination of entropy fuzzy and F-PROMETHEE techniques
}

\author{
Amin Shahmardan ${ }^{1}$, Mohammad Hendijani Zadeh ${ }^{2}$ \\ ${ }^{1}$ Department of Industrial Engineering and Management Systems, Amir Kabir University of Technology, Tebran (Iran) \\ ${ }^{2}$ Department of Financial Management, School of Management, University of Tehran, Tehran (Iran) \\ amin.shabmardan@aut.ac.ir,.bendijani@ut.ac.ir
}

Received: July 2013

Accepted: September 2013

\section{Abstrad:}

Purpose The intention of this paper is the presentation of a new integrated approach for solving a multi attribute decision making problem by the use of entropy fuzzy and F-PROMETHEE (fuzzy preference ranking method for enrichment evaluation) techniques.

Design/mathoddogy/approadr In these sorts of multi attribute decision making problem, a number of criteria and alternatives are put forward as input data. ranking of these alternatives according to mentioned criteria is regarded as the outcome of solving these kinds of problems. initially, weights of criteria are determined by implementation of entropy fuzzy method. according to determined weights, F-PROMETHEE method is exerted to rank these alternatives in terms of desirability of DM (decision maker).

Findings: Being in an uncertain environment and vagueness of DM's judgments, lead us to implement an algorithm which can deal with these constraints properly. this technique namely called entropy fuzzy as a weighting method and F-PROMETHEE is performed to fulfill this approach more precisely according to tangible and intangible aspects. the main finding of applied approach is the final ranking of alternatives helping DM to have a more reliable decision. 
Originality/Value The main contribution of this approach is the giving real significance to DM's attitudes about mentioned criteria in determined alternatives which is not elucidate in former approaches like Analytical Hierarchy Process (AHP). furthermore, previous methods like Shanon entropy do not pay attention sufficiently to satisfaction degree of each criterion in proposed alternatives, regarding to DM's statements. comprehensive explanations about these procedures have been made in miscellaneous sections of this article.

Keywards entropy fuzzy, F-PROMETHEE, multi criteria decision making, fuzzy set, decision maker, fuzzy environment

\section{Introduction}

Multiple criteria decision making (MCDM) is a powerful tool used widely for appraisement and ranking problems containing multiple, usually conflicting, criteria (Bilsel, Buyukozkan, \& Ruan, 2006). Selecting a proper method requires an insight analysis among available MCDM techniques. Multi Criteria Decision Making (MDCM) methods have been implemented frequently in terms of solving different problems in both of certain and uncertain environments. Additionally, it is increasingly used in environmental policy evaluation as (a) it offers the possibility to deal with intricate issues, (b) it incorporates criteria that are difficult to monetize, (c) it represents a holistic view incorporating tangible as well as intangible (or 'fuzzier') aspects, often neglected by other evaluation techniques such as AHP (Munda, 2004).

One of the problems which has always been controversial for a manufacturer as a Decision Maker (DM), is the selection of a project among a number of projects according to tangible and intangible (fuzzier) aspects. This problem has been put forward as a numerical example in this paper. When a manufacturer is determined to choose a project, different prospects of those projects have to be scrutinized to select the most profitable one. First of all, manufacturer should elucidate the criteria of appraisement and weight them regarding to their importance degree. For weighting these specific criteria, a great number of techniques have been utilized like Analytical Hierarchy Process (AHP) which was developed by Saaty (1982) results in attribution of weights to the specific criteria (Macharis, Springael, De Brucker \& Verbeke, 2004; Turcksin, Bernardini \& Macharis, 2011). In former works, Chakraborty and Banik (2006) employed AHP technique in selecting the optimal material handling equipment under a specific handling environment and performed sensitivity analysis to identify the most critical and robust criteria in the selection process. In another study held by Ayag and Ozdemir (2006), an intelligent approach is proposed, where both techniques; fuzzy logic and AHP are come together, referred to as fuzzy AHP, and was used for a machine tool selection problem. Generally, we are facing with different uncertain aspects due to having incomplete information about them. In the last few years, numerous 
studies attempting to handle this uncertainty. imprecision, and subjectiveness have been carried out basically by means of fuzzy set theory, as fuzzy set theory might provide the flexibility needed to represent the imprecision or vague information resulting from a lack of knowledge or information. The application of fuzzy set theory to multi criteria evaluation methods under the framework of utility theory has proven to be an effective approach. For instance as it mentioned before, fuzzy theory and AHP are combined to become the Fuzzy AHP (FAHP) method (Lee, Chen, \& Chang, 2008), which is a fuzzy extension of AHP, and was developed to solve hierarchical fuzzy problems. Thus, necessity of using theory of fuzzy introduced by Zadeh (1965) is inevitable. Even though certain criteria are expressed in quantitative preferences, some of them are stated in a qualitative observation which should be interpreted quantitatively. In other words, because of the vagueness and uncertainty of decision maker's judgements, fuzzy number logic is applied. In this paper, Entropy Weight under Intuitionistic Fuzzy environment method is employed for weight attributions. After conducting first stage, we are in need of the one of the ranking methods for our Multi Criteria Decision Analysis (MCDA).Preference Ranking Organization Method for Enrichment Evaluation (PROMETHEE) is considered as one of the most efficient and suitable ranking methods (Bilsel et al., 2006). Flexibility and simplicity of this outranking method makes it more desirable for its users (Geldermann, Spengler \& Rentz, 2000). PROMETHEE technique has been repeatedly in various fields like portfolio selection problems (Vetschera \& de Almeida, 2011), stock trading issues (Chaharsoughi, Albadvi \& Esfahanipour, 2006), Abu-Taleb and Mareschal (1995) conducted an application for the PROMETHEE method to evaluate water resource projects. Al-Kloub and Abu-Taleb (1998) use PROMETHEE for project portfolios in the water resource context. A leakage management strategy of water distribution networks has been analyzed by Morais and de Almeida (2007) using PROMETHEE in a group decision context.

F-PROMETHEE (Fuzzy Preference Ranking Organization Method for Enrichment Evaluation) is the extension of PROMETHEE under dominance of fuzzy environment. We use F-PROMETHEE method to deal with the vagueness caused from the linguistic terms which are used in expressing the difference among the alternatives. By use of F-PROMETHEE, these alternatives (projects) are ranked from best to worst to make it easier decision making for DM in uncertain environment (Yilmaz \& Dağdeviren, 2011).

This paper embodies four remarkable sections; first of all, there are some explanations about Entropy Fuzzy method and Fuzzy Theory. Next segment of this part is devoted to some clarifications about PROMETHEE and F-PROMETHEE techniques and its necessary requisite of them. The new proposed approach is described in section 3 of this paper. While, by putting forward an illustrative example, all of the mentioned methods are utilized to solve a MCDM problem and it is attempted to be more familiar with practical use of these techniques in $4^{\text {th }}$ section of this paper. Ultimately the conclusion about explained techniques is made, in last part of this paper. 


\section{Principles of Fuzzy Entropy and F-PROMETHEE}

\subsection{Fuzzy Entropy}

According to the second law of thermodynamic, a system has a tendency to become more disordered over time, which declares the entropy of system cannot subside inherently. Shanon (1948) was the first one who demonstrated the concept of Entropy in systems by his communication theory. Entropy is one of the characteristic of any stochastic system and now days, it is considered as one of the most prevalent applications in various fields. Most of the time, exact values of parameters are obscure, hence, uncertainty increases dramatically. By the use of fuzzy numbers and arithmetic, we can deal with this situation properly. Fuzzy entropy was introduced by Zadeh (1968), later De Luca and Termini (1972) introduced some of its requirements which helped us to have a better intuition for degree of fuzziness. In Zadeh's fuzzy set, a degree of membership value between zero and one is assigned to each element. Gau and Buerher (1993) suggested the concept of vague sets. Bustince and Burillo (1996) pointed to the coincidence of intuitionistic fuzzy sets (IFSs) with concept of vague sets. Some measures of Entropy Fuzzy and dependent properties of that have been suggested by Kapur (1997), Singpurwalla and Booker (2004), Emptoz (1981) etc. In this part, we review some of these definitions.

Definition 1. An IFS $A$ in the universe of discourse $X$ is defined with the following form (Atanassov, 1986):

$$
A=\left\{\left\langle x, \mu_{A}(x), v_{A}(x)\right\rangle \mid x \in X\right\}
$$

Where

$$
\mu_{A}: X \rightarrow[0,1], v_{A}: X \rightarrow[0,1]
$$

With the condition

$$
0 \leq \mu_{A}(x)+v_{A}(x) \leq 1, \forall x \in X
$$

The numbers $\mu_{A}(x)$ and $v_{A}(x)$ denote the membership degree and non-membership degree of $x$ to $A$, respectively.

Obviously, each ordinary fuzzy set may be written as: (Hung \& Chen, 2009)

$$
\left\{\left\langle x, \mu_{A}(x), 1-\mu_{A}(x)\right\rangle \mid x \in X\right\}
$$

For each IFS $A$ in $X$. We will call (5) the intuitionistic index of $x$ in $A$. It is a measure of hesitancy degree of $x$ to $A$. It is obvious that $0 \leq \pi_{A}(x) \leq 1$ for each $x \in X$.

$$
\pi_{A}(x)=1-\mu_{A}(x)-v_{A}(x)
$$


For convenience of notation, $\operatorname{IFSs}(x)$ is denoted as the set of all $\operatorname{IFSs}(x)$ in $X$. (Atanassov, 1986).

Definition 2 (De, Biswas \& Roy, 2000). For every $A \in \operatorname{IFSs}(x)$, the $\operatorname{IFS} \lambda A$ for any positive real number $\lambda$ is defined as follows:

$$
\lambda A=\left\{\left\langle x, 1-\left(1-\mu_{A}(x)\right)^{\lambda},\left(v_{A}(x)\right)^{\lambda}\right\rangle \mid x \in X\right\}
$$

Shannon (1948) proposed the entropy function according following formulation:

$$
H\left(p_{1}, p_{2}, \ldots, p_{n}\right)=-\sum_{i=1}^{n} p_{i} \log \left(p_{i}\right)
$$

$\left(P_{1}, P_{2}, \ldots, P_{\mathrm{n}}\right)$ represents the probabilities of random variable calculated from a probability function P. Based on the Shannon function, De Luca and Termini (1972) defined a non probability entropy function on a finit universal set.

$$
\begin{gathered}
X=\left\{x_{1}, x_{2}, \ldots, x_{n}\right\} \\
E_{L T}(A)=-k \sum_{i=1}^{n}\left[\mu_{A}\left(x_{i}\right) \ln \mu_{A}\left(x_{i}\right)+\left(1-\mu_{A}\left(x_{i}\right)\right) \ln \left(1-\mu_{A}\left(x_{i}\right)\right)\right], k>0
\end{gathered}
$$

Following equation shows the measure of intuitionistic fuzzy by Vlachos and Sergiadis (2007) that satisfied the four mentioned requirements.

$$
E_{L T}^{I F S}(A)=-1 /(n \ln 2) \sum_{i=1}^{n}\left[\mu_{A}\left(x_{i}\right) \ln \mu_{A}\left(x_{i}\right)+v_{A}\left(x_{i}\right) \ln v_{A}\left(x_{i}\right)-\left(1-\pi_{A}\left(x_{i}\right)\right) \ln \left(1-\pi_{A}\left(x_{i}\right)\right)-\pi_{A}\left(x_{i}\right) \ln 2\right]
$$

In this paper, computation of weights $t$ of criteria is done by the Entropy Fuzzy method. Let $W=\left(w_{1}, w_{2}, \ldots, w_{n}\right)$ be the weighting vector of criteria $\left(\sum_{j=1}^{n} w_{j}=1\right)$.

$w_{j} \geq 0$.

$C=\left\{C_{1}, C_{2}, \ldots, C_{\mathrm{n}}\right\}$ represents the criteria.

$$
A_{i}=\left\{\left\langle C_{j}, \mu_{A_{i}}\left(C_{j}\right), v_{A_{i}}\left(C_{j}\right)\right\rangle \mid C_{j} \in C\right\}, \quad i=1,2, \ldots, m
$$

$A_{i}$ represents the alternatives (projects). $\mu_{A i}$ and $v_{A i}$ show the degree which satisfies and not satisfies the criterion $C_{j}$.

$$
\begin{gathered}
\mu_{A_{i}}\left(C_{j}\right) \in[0,1], v_{A_{i}}\left(C_{j}\right) \in[0,1] \\
\mu_{A_{i}}\left(C_{j}\right)+v_{A_{i}}\left(C_{j}\right) \in[0,1]
\end{gathered}
$$


$\pi_{A i}\left(C_{j}\right)=1-\mu_{A i}(C j)-v_{A i}(C j)$ indicates that higher $\pi_{A i}\left(C_{j}\right)$ results in more hesitancy margin of DM about impact of $A_{i}$ respect to $C_{j}$. Next step is to use following formula to exhibit $E_{L T}^{I F S}\left(C_{j}\right)$ of any criterion.

Where $j=1,2, \ldots, n$ and $\frac{1}{(m \ln 2)}$ is a constant which assures $0 \leq E_{L T}^{I F S}\left(C_{j}\right) \leq 1$.

$$
E_{L T}^{I F S}\left(C_{j}\right)=-1 /(m \cdot \ln 2) \sum_{i=1}^{m}\left[\mu_{i j}\left(C_{j}\right) \ln \mu_{i j}\left(C_{j}\right)+v_{i j}\left(C_{j}\right) \ln v_{i j}\left(C_{j}\right)-\left(1-\pi_{i j}\left(C_{j}\right)\right) \ln \left(1-\pi_{i j}\left(C_{j}\right)\right)-\pi_{i j}\left(C_{j}\right) \ln 2\right]
$$

$m$ is the number of projects which is 3 in our problem. Finally $d_{j}$ (degree of divergence) is prepared by specific definition on criterion $C_{j}$.

$$
d_{j}=1-E_{L T}^{I F S}\left(C_{j}\right), j=1,2, \ldots, n
$$

The value of $d_{j}$ represents the onherent contrast intensity of criterion $C_{j}$, then the entropy weight of the $j$ th criterion is $w_{j}=d_{j} /\left(\sum_{j=1}^{n} d_{j}\right)$

\subsection{PROMEETHEE and F-PROMETHEE methods:}

PROMETHHE was introduced by Brans (1982) and later extended by Barns and Mareschal (1994). It is considered as one of the outranking methods. This technique is regarded as a reaction to complete aggregation (MAUT) methods (Macharis, Verbeke \& De Brucker, 2004). PROMETHEE technique is one of the intuitive methods of MCDM which is so much intelligible for DM (Ballis \& Mavrotas, 2007).

For using this MADM technique, out following steps are carried out:

1. Having a table included specific alternatives as well as certain criteria for assessment.

2. Preference function should be defined $P_{j}(a, b)$ which states deviation between two alternatives $(a, b)$ on a particular criterion $g_{j}$ into a preference degree ranging 0 to 1 .

3. Choosing one of the six possible shape of preference functions put forward by Brans, Vincke and Mareschal (1986) (usual shape, U-shape function, V-shape function, level function, linear function and Gaussian function)

$$
P_{j}(a, b)=G_{j}\left(f_{j}(a)-f_{j}(b)\right) 0 \leq P_{j}(a, b) \leq 1
$$

$f_{j}(a)-f_{j}(b)$ expresses the deviation score of two alternatives on a certain criterion. 
4. By knowing the weights of criteria calculated in previous part (Entropy Fuzzy) we define the following formulas:

$$
\begin{gathered}
\pi(a, b)=\sum_{j=1}^{k} w_{j} P_{j}(a, b) \\
\varphi^{+}(a)=1 /(n-1) \sum_{b} \pi(a, b) \\
\varphi^{-}(a)=1 /(n-1) \sum_{b} \pi(b, a) \\
\varphi(a)=\varphi^{+}(a)-\varphi^{-}(a)
\end{gathered}
$$

$\varphi^{+}(a)$ and $\varphi^{-}(a)$ represent positive and negative preference flow for each alternative which measure how an alternative (a) is out ranking (formula 17) or out ranked (formula 18).

$\varphi(a)$ (formula 19) displays the value function and alternative (a) will be more attractive, if its value function has a higher amount.

In partial ranking, we face with three situations in terms of superiority of alternative (a) to alternative (b) (formula 20), being indifferent two alternatives (formula 21), being incomparable two alternatives (formula 22) (Brans \& Vincke, 1985).

$$
\begin{aligned}
& \left\{\begin{array}{lll}
\phi^{+}(a)>\phi^{+}(b) & \text { and } & \phi^{-}(a)<\phi^{-}(b) \\
\phi^{+}(a)>\phi^{+}(b) & \text { and } & \phi^{-}(a)=\phi^{-}(b) \\
\phi^{+}(a)=\phi^{+}(b) & \text { and } & \phi^{-}(a)<\phi^{-}(b)
\end{array}\right. \\
& \left\{\begin{array}{lll}
\phi^{+}(a)=\phi^{+}(b) & \text { and } & \phi^{-}(a)=\phi^{-}(b)
\end{array}\right. \\
& \left\{\begin{array}{lll}
\phi^{+}(a)>\phi^{+}(b) & \text { and } & \phi^{-}(a)>\phi^{-}(b) \\
\phi^{+}(a)<\phi^{+}(b) & \text { and } & \phi^{-}(a)<\phi^{-}(b)
\end{array}\right.
\end{aligned}
$$

On the other hand by use of PROMETHEE II, we only measure the $\phi^{\text {net }}$ and it will be our main evaluation application for decision making. Every alternative has a higher $\phi^{\text {net }}$ it has a better position in ultimate ranking and we have a complete ranking.

When a DM states his experiences and considerations in linguistic terms as input data, the obscurity and fuzziness are taken place. In such a circumstance, probability of making mistake in our assessment arises incredibly. The solution is the use of F-PROMETHHE that is the combination of fuzziness and PROMETHEE.

In this paper F-PROMETHE is implemented as it was suggested by Goumas and Lygerou (2000). The procedures of F-PROMETHEE as same as PROMETHEE, but fuzzy logic gets involved in this methodology as well. By using this technique, it will be easier for DM to interpret his qualitative attitudes and information to mathematical expressions

$x=(a, m, b)$ is the presentation of a fuzzy number which is shown in figure 1. 
$x$ is a variable belongs to the fuzzy set and its membership function $f(x)$ has the value $[0,1]$.

For $x<a$ or $x>b, x$ does not belong to the set.

For $[x \leq a \leq b]$ the membership degree is indicated by membership function that varies between 0 to 1 .

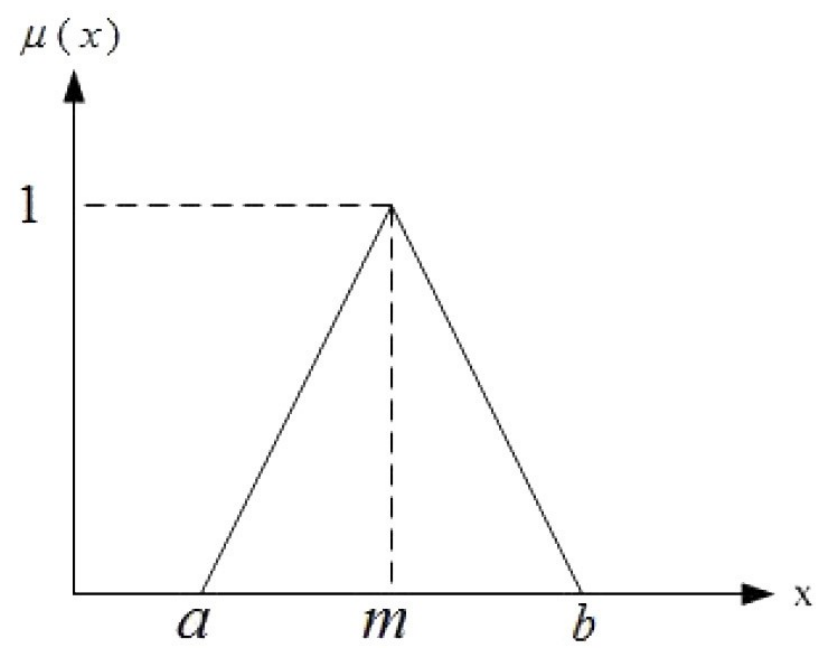

Figure 1. Presentation of fuzzy number $x=(a, m, b)$

In our paper, the assumption is that weights of criteria were brought by Entropy Fuzzy and preference thresholds ( $q$ and $p$ ) are crisp numbers.

According to the properties of our MCDM problem, linear preference function (type5) with indifferences and stringent preference thresholds ( $q$ and $p$ ) is our best choice to be employed.

$$
\left\{\begin{array}{lll}
P(a, b)=0 & \text { for } & d \leq q \\
P(a, b)=(d-q) /(p-q) & \text { for } & q \leq d \leq p \\
P(a, b)=1 & \text { for } & d \geq q
\end{array}\right.
$$

In F-PROMETHEE $(d)$ exhibits the differences between two fuzzy numbers of $(a, b)$ which results in a fuzzy number such as $(n, c, d)$. Above equations are transformed to the following equations respectively;

$$
\left\{\begin{array}{lll}
P(a, b)=0 & \text { for } & n-c \leq q \\
P(a, b)=(d-q) /(p-q) & \text { for } & q \leq n-c \\
P(a, b)=1 & \text { for } & n+d \geq q
\end{array} \text { and } n+d \leq p\right.
$$

Essential formulas for basic computations with fuzzy number (DuBois \& Prade, 1978) are characterized in table 1. 


\begin{tabular}{|l|l|}
\hline Addition & $(m, a, b)_{L R} \oplus(n, c, d)_{L R}=(m+n, a+c, b+d)_{L R}$ \\
\hline Opposite & $-(m, a, b)_{L R}=(-m, a, b)_{L R}$ \\
\hline Subtraction & $(m, a, b)_{L R}-(n, c, d)_{L R}=(m-n, a+c, b+d)_{L R}$ \\
\hline Multiplication By Scalar & $(m, a, b)_{L R} \times(n, 0,0)_{L R}=(m n, a n, b n)_{L R}{ }_{L R}$ \\
\hline Multiplication By Fuzzy & \\
\hline for $\quad m>0, n>0$ & $(m, a, b)_{L R} \otimes(n, c, d)_{L R} \approx(m n, c m+a n, d m+b n)_{L R}$ \\
\hline for $\quad m<0, n>0$ & $(m, a, b)_{L R} \otimes(n, c, d)_{L R} \approx(m n, a n-d m, b n-c m)_{L R}$ \\
\hline for $\quad m<0, n<0$ & $(m, a, b)_{L R} \otimes(n, c, d)_{L R} \approx(m n,-b n-d m,-a n-c m)_{L R}$ \\
\hline Inverse for $(m>0)$ & $(m, a, b)_{L R}^{-1} \approx\left(m^{-1}, b m^{2}, a m^{-2}\right)_{L R}$ \\
\hline
\end{tabular}

Table 1. Basic fuzzy operations

Eventually, in application of F-PROMETHEE, we are given some fuzzy numbers. According to the mentioned computations, $d$ value will be calculated. Right now this fuzzy numbers should be changed to the defuzzy forms according to following formula:

$$
F(a, m, b)=(a+2 \mathrm{~m}+b) / 4
$$

One after that, left stages of PROMETHEE are performed and $\phi^{+}, \phi^{-}$and $\phi^{\text {net }}$ will be measured regarding stated formulas formerly.

\section{Proposed Entropy _F-PROMETHEE integrated approach}

As it has mentioned before, determination of weights related to criteria should be computed by intuitionistic fuzzy entropy which was presented by Vlachos and Sergiadis (2007). This step should be taken according information given to the contractor (DM) $(u, v)$. Subsequently, these criteria as well as their weight are employed to measure $\phi^{+}, \phi^{-}$and $\phi^{\text {net }}$ of every alternative (project). Final decision is made by comparison of alternatives $\phi^{\text {net }}$, All data are fuzzy numbers and they should be changed to defuzzy forms. Therefore we have to conduct following stages:

1. Data Collection: The essence of this stage is dependent on experiences and considerations of manufacturer (DM). Every alternative has a $u$ and $v$ degrees which satisfy or not satisfy respectively a specific criterion.

2. Assigning weights to the criteria intuitionistic fuzzy entropy. These calculations are done regarded to mentioned formulas.

3. Measuring the $\phi^{+}, \phi^{-}$and $\phi^{\text {net }}$ of every alternative (project).

4. Ranking of projects according to brought amounts. 


\section{Numerical example of proposed approach}

In this stage, with the purpose of having a better understanding about alluded procedures, a decision-making problem is solved. In our illustrative instance, we have a manufacturer who is going to select one of the three proposed projects according to six mentioned criteria (Cost Performed, Conduction Risk, reputation impact, period of performing the project, similarity with former projects, and rate of return). $C_{j}$ and $A_{i}$ are the symbols of criteria and project respectively.

Following diagram (Figure 2) depicts step-by-step stages tracked for solving a MCDM problem by the use Entropy Fuzzy and F-PROMETHEE method.

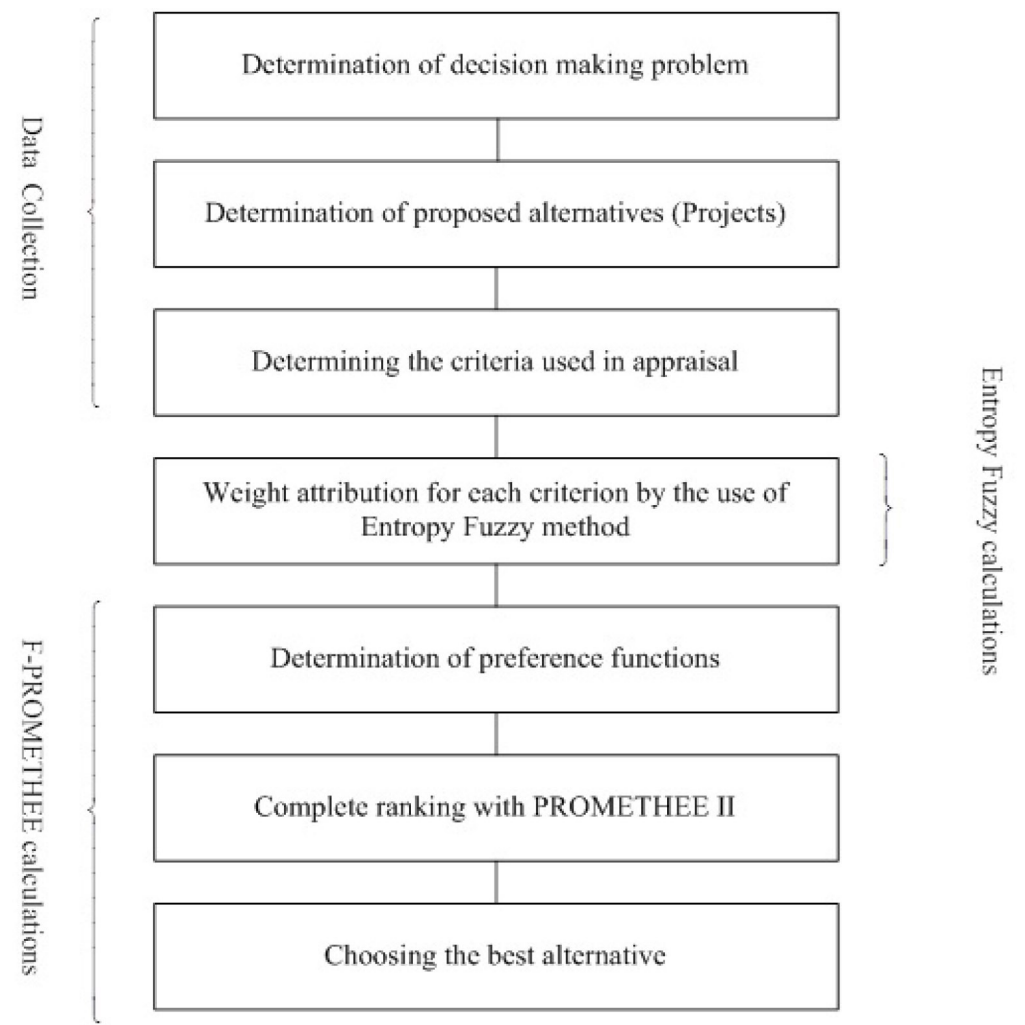

Figure 2. Schematic depiction of the new proposed approach for solving a MCDM problem

Entropy Fuzzy Computations: As we discussed previously, we use Intuitionistic Fuzzy Entropy for weighting the criteria. Following table represents the amount of $\left(\mu_{A j}, v_{A j}, \pi_{A j}\right)$ of each project in every criterion.

\begin{tabular}{|c|c|c|c|c|c|c|c|c|c|c|c|c|c|c|c|c|c|c|}
\hline & \multicolumn{3}{|c|}{$\mathrm{C}_{1}$} & \multicolumn{3}{|c|}{$C_{2}$} & \multicolumn{3}{|c|}{$\mathrm{C}_{3}$} & \multicolumn{3}{|c|}{$\mathrm{C}_{4}$} & \multicolumn{3}{|c|}{$C_{5}$} & \multicolumn{3}{|c|}{$\mathrm{C}_{6}$} \\
\hline & $\mu_{A 1}$ & $V_{A 1}$ & $\Pi_{A 1}$ & $\mu_{A 2}$ & $V_{A 2}$ & $\Pi_{A 2}$ & $\mu_{A 3}$ & $V_{A 3}$ & $\Pi_{A 3}$ & $\mu_{A 4}$ & $V_{A 4}$ & $\Pi_{\mathrm{A} 4}$ & $\mu_{A 5}$ & $V_{A 5}$ & $\Pi_{A 5}$ & $\mu_{A G}$ & $V_{A G}$ & $\Pi_{A G}$ \\
\hline$A_{1}$ & 0.6 & 0.1 & 0.3 & 0.8 & 0.1 & 0.1 & 0.7 & 0.2 & 0.1 & 0.55 & 0.25 & 0.2 & 0.6 & 0.1 & 0.3 & 0.8 & 0.1 & 0.1 \\
\hline$A_{2}$ & 0.8 & 0.1 & 0.1 & 0.7 & 0.15 & 0.15 & 0.65 & 0.25 & 0.15 & 0.5 & 0.3 & 0.2 & 0.65 & 0.2 & 0.15 & 0.75 & 0.2 & 0.05 \\
\hline $\mathrm{A}_{3}$ & 0.85 & 0.1 & 0.05 & 0.75 & 0.1 & 0.15 & 0.75 & 0.15 & 0.1 & 0.5 & 0.2 & 0.3 & 0.7 & 0.1 & 0.2 & 0.7 & 0.1 & 0.2 \\
\hline
\end{tabular}

Table 2. Demostration of degrees which satisfy and not satisfy criterion $C_{j}$ in project $A_{i}$

By the use of Entropy Fuzzy procedures following weights of criteria are achieved. 


\begin{tabular}{|c|c|c|c|c|c|c|}
\hline Criteria & $\mathbf{C}_{1}$ & $\mathbf{C}_{2}$ & $\mathbf{C}_{3}$ & $\mathbf{C}_{4}$ & $\mathbf{C}_{5}$ & $\mathbf{C}_{6}$ \\
\hline Weights & 0.238 & 0.221 & 0.131 & 0.042 & 0.162 & 0.206 \\
\hline
\end{tabular}

Table 3. Brought amount of weights of criteria

Right now according to brought weights of criteria and input data (fuzzy numbers) related to specific projects represented in following table, F-PROMETHEE method is exerted to have a final ranking to proposed projects for manufacturer (DM). Qualitative aspects concerned to manufacturer's preferences are interpreted according to following fuzzy numbers. Qualitative statements are listed as VG: Very Good, G: Good, M: Moderate, H: High, VH: Very High, VL: Very Low, L: Low, ME: Medium, HI: High Impact, and VHI: Very High Impact.

\begin{tabular}{|c|c|c|c|}
\hline Qualitative statements & Equivalent fuzzy numbers & Qualitative statements & Equivalent fuzzy numbers \\
\hline VG & $(0,0.1,0.2)$ & VL & $(0,0.1,0.2)$ \\
\hline G & $(0.2,0.3,0.45)$ & $\mathrm{L}$ & $(0.2,0.35,0.4)$ \\
\hline M & $(0.45,0.5,0.6)$ & ME & $(0.4,0.5,0.6)$ \\
\hline H & $(0.6,0.75,0.85)$ & HI & $(0.6,0.7,0.8)$ \\
\hline VH & $(0.85,0.9,1)$ & VHI & $(0.8,0.9,1)$ \\
\hline
\end{tabular}

Table 4. Linguistic scale for importance

\begin{tabular}{|c|c|c|c|c|c|c|}
\hline Criteria & $\mathrm{C}_{1}$ & $\mathrm{C}_{2}$ & $\mathrm{C}_{3}$ & $\mathrm{C}_{4}$ & $\mathrm{C}_{5}$ & $\mathrm{C}_{6}$ \\
\hline $\begin{array}{c}\text { Objective } \\
\text { Function }\end{array}$ & Min & Min & Max & Min & Max & Max \\
\hline $\mathrm{A}_{1}$ & {$[800,1000,1200]$} & $\mathrm{G}$ & ME & {$[15,17,18]$} & $\mathrm{L}$ & {$[0.4,0.5,0.6]$} \\
\hline $\mathrm{A}_{2}$ & {$[700,800,1000]$} & $\mathrm{M}$ & $\mathrm{HI}$ & {$[14,16,17]$} & $\mathrm{ME}$ & {$[0.45,0.55,0.6]$} \\
\hline $\mathrm{A}_{3}$ & {$[750,750,900]$} & $\mathrm{H}$ & $\mathrm{HI}$ & {$[15,18,20]$} & $\mathrm{ME}$ & {$[0.35,0.45,0.55]$} \\
\hline
\end{tabular}

Table 5. Fuzzy numbers and qualitative statements related to every $C_{j}$ in every $A_{i}$

As it was put forward formerly, regarding the calculated $\phi^{N e t}$ concerned to projects, they will be ranked respectively best to worst.

\begin{tabular}{|c|c|c|c|c|} 
& $\phi^{+}$ & $\phi^{-}$ & $\phi^{\text {Net }}$ & Ranking \\
\hline$A_{1}$ & 0.1078740 & 0.2700310 & -0.162157 & 3 \\
\hline$A_{2}$ & 0.31005 & 0.0137445 & 0.2963055 & 1 \\
\hline$A_{3}$ & 0.1319045 & 0.266053 & -0.1341485 & 2 \\
\hline
\end{tabular}

Table 5. F-PROMETHEE flows

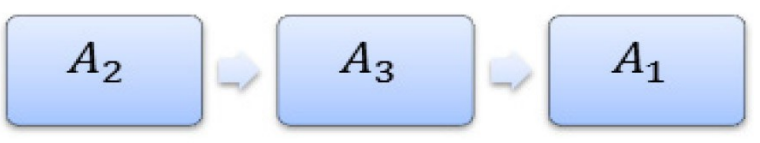

Figure 3. Total Ranking 


\section{Conclusion}

In this paper, a new approach to solve the MCDM problems has been presented. In an uncertain and stochastic environment, using fuzzy theory and its applications are justifiable. A weighting method (Entropy Fuzzy) and an outranking technique (F-PROMETHEE) were explained thoroughly in previous sections. An illustrative example was put forward to become more acquaint with practical use of integrated approach. A DM (manufacturer) should select one of the proposed alternatives (projects) according to certain criteria of those projects. In this numerical example, by the use of Entropy Fuzzy technique, weights of criteria were determined and F-PROMETHEE method was implemented to have a final ranking of projects regarding brought numbers. Quantitative and qualitative aspects which are concerned to DM's preferences are better perused in asserted methods; subsequently a more reliable consequence is accomplished. If we are supposed to mention to the main contribution of proposed approach, we can suggest; Being in an uncertain environment and vagueness of DM's judgments, lead us to implement an algorithm which can deal with these constraints properly. This technique namely called Entropy Fuzzy as a weighting method and FPROMETHEE is exerted to fulfill this approach more precisely regarding to tangible and intangible aspects. On the other hand, former techniques like Shannon Entropy as a weighting method did not comprise the DM's opinions about criteria and projects thoroughly rather than the proposed approach.

\section{References}

Abu-Taleb, M.F., \& Mareschal B. (1995). Water resources planning in the Middle East: application of the PROMETHEE $\vee$ multicriteria method. European Journal of Operational Research, 81(3), 500-11. http://dx.doi.org/10.1016/0377-2217(94)00007-Y

Al-Kloub, B., \& Abu-Taleb, M.F. (1998). Application of multicriteria decision aid to rank the Jordan-Yarmouk basin co-riparians according to the Helsinki and ILC rules. Water International, 23(3), 164-73. http://dx.doi.org/10.1080/02508069808686763

Atanassov, K.T. (1986). Intuitionistic fuzzy sets. Fuzzy sets and systems, 20(1), 87-96. http://dx.doi.org/10.1016/S0165-0114(86)80034-3

Ayag, Z., \& Ozdemir, R.G. (2006). A fuzzy AHP approach to evaluating machine tool alternatives. Journal of Intelligent Manufacturing, 17, 179-190. http://dx.doi.org/10.1007/s10845005-6635-1

Ballis, A., \& Mavrotas, G. (2007). Freight villag design using the multicriteria method PROMETHEE. Operational Research, 7(2), 213-231. http://dx.doi.org/10.1007/BF02942388 
Bilsel, R.U., Buyukozkan, G., \& Ruan, D. (2006). A fuzzy preference-ranking model for a quality evaluation of hospital web sites. International Journal of Intelligent Systems, 21, 1181-1197. http://dx.doi.org/10.1002/int.20177

Brans, J.P. (1982). L'ingénierie de la décision. Elaboration d'instruments d'aide à la décision. Méthode PROMETHEE. In Nadeau, R., Landry, M. (Eds.). L'aide à la décision: Nature, instruments et perspectives d'avenir. Presses de I'Université Laval, Québec, Canada, 183-214.

Brans, J.P., \& Mareschal, B. (1994). The PROMCALC and GAIA decision support system for MCDA. Decision Support Systems, 12, 297-310. http://dx.doi.org/10.1016/0167-9236(94)90048-5

Brans, J.P., \& Vincke, Ph. (1985). A preference ranking organization method: the PROMETHEE method. Management Science, 31, 647-656. http://dx.doi.org/10.1287/mnsc.31.6.647

Brans, J.P., Vincke, Ph., \& Mareschal, B. (1986). How to select and how to rank projects: the PROMETHEE method. European Journal of Operational Research, 24, 228-238. http://dx.doi.org/10.1016/0377-2217(86)90044-5

Bustince, H., \& Burillo. P. (1996). Vague sets are intuitionistic fuzzy sets. Fuzzy Sets and Systems, 79, 403-405. http://dx.doi.org/10.1016/0165-0114(95)00154-9

Chaharsoughi, S.K., Albadvi, A., \& Esfahanipour, A. (2006). Portofolio selection in stock exchange through industries and companies ranking. Amirkabir, -sid.ir.

Chakraborty, S., \& Banik, D. (2006). Design of a material handling equipment selection model using analytical hierarchy process. International Journal of Advanced Manufacturing Technologies, 28, 1237-1245. http://dx.doi.org/10.1007/s00170-004-2467-y

De Luca, A., \& Termini, S. (1972). A definition of non-probabilistic entropy in setting of fuzzy set theory. Information and Control, 20, 301-312. http://dx.doi.org/10.1016/S0019-9958(72)901994

De, S.K., Biswas, R., \& Roy, A.R. (2000). Some operations on intuitionistic fuzzy sets. Fuzzy Sets and Systems, 114(3), 477-484. http://dx.doi.org/10.1016/S0165-0114(98)00191-2

DuBois, D., \& Prade, H. (1978). Operations on fuzzy numbers. International Journal of Systems Science, 9, 613-626. http://dx.doi.org/10.1080/00207727808941724

Emptoz, H. (1981). Non-probabilistic entropies and indetermination process in the setting of fuzzy set theory. Fuzzy Sets and Systems, 5, 307-317. http://dx.doi.org/10.1016/01650114(81)90058-0

Gau, W.L., \& Buehrer, D.J. (1993). Vague sets. IEEE Transactions on Systems Man and Cybernetics, 23(2), 610-614. http://dx.doi.org/10.1109/21.229476 
Geldermann, J., Spengler, T., \& Rentz, O. (2000). Fuzzy outranking for environmental assessment. Fuzzy Set Systems, 115, 45-65. http://dx.doi.org/10.1016/S0165-0114(99)00021-4

Goumas, M., \& Lygerou, V. (2000). An extension of the PROMETHEE method for decision making in fuzzy environment: Ranking of alternative energy exploitation projects. European Journal of Operational Research, 123, 606-613. http://dx.doi.org/10.1016/S0377-2217(99)00093-4

Hung, C.C., \& Chen, L.H. (2009). A Fuzzy TOPSIS Decision Making Model with Entropy Weight under Intuitionistic Fuzzy Environment. International Multi Conference of Engineers and Computer Scientists, 1, 13-16.

Kapur, J.N. (1997). Measures of Fuzzy Information. Mathematical Sciences Trust Society, New Delhi.

Lee, A.H.I., Chen, W.-C., \& Chang, C.-J. (2008). A fuzzy AHP and BSC approach for evaluating performance of IT department in the manufacturing industry in Taiwan. Expert Systems with Applications, 34, 96-107. http://dx.doi.org/10.1016/j.eswa.2006.08.022

Macharis, C., Verbeke, A., \& De Brucker, K. (2004). The strategic evaluation of new technologies through multicriteria analysis: the Advisors case. Research in Transportation Economics, 8, 443-462. http://dx.doi.org/10.1016/S0739-8859(04)08019-9

Macharis, C., Springael, J., De Brucker, K., \& Verbeke, A. (2004). PROMETHEE and AHP: The design of operational synergies in multi criteria analysis. Strengthening PROMETHEE with ideas of AHP. European Journal of Operational Research, 153(2), 307-317. http://dx.doi.org/10.1016/S0377-2217(03)00153-X

Morais, D.C., \& de Almeida, A.T. (2007). Group decision-making for leakage management strategy of water network. Resources, Conservation and Recycling, 52(2), 441-459. http://dx.doi.org/10.1016/j.resconrec.2007.06.008

Munda, G. (2004). Social multi-criteria evaluation (SMCE): methodological foundations and operational consequences. European Journal on Operational Research, 158(3), 662-677. http://dx.doi.org/10.1016/S0377-2217(03)00369-2

Saaty, T.L. (1982). Decision making for leaders. Wadsworth, Belmont: Lifetime learning publications.

Shannon, C.E. (1948). A mathematical theory of communication. Bell System Technical Journal, 27, 379-423, 623-659. http://dx.doi.org/10.1002/j.1538-7305.1948.tb00917.x

Singpurwalla, N.D., \& Booker, J.M. (2004). Membership functions and probability measures of fuzzy sets. Journal of the American Statistical Association, 99, 867-889. http://dx.doi.org/10.1198/016214504000001196 
Turcksin, L., Bernardini, A., \& Macharis, C. (2011). A combined AHP-PROMETHEE approach for selecting the most appropriate policy scenario to stimulate a clean vehicle fleet. Procedia Social and Behavioral Sciences, 20, 954-965. http://dx.doi.org/10.1016/j.sbspro.2011.08.104

Vetschera, R., \& de Almeida, A.T. (2011). Journal of Computer and Operation Research.

Vlachos, I.K., \& Sergiadis, G.D. (2007). Intuitionistic fuzzy information - Applications to pattern recognition, Pattern Recognition Letters, 28, 197-206. http://dx.doi.org/10.1016/j.patrec.2006.07.004

Yilmaz, B., \& Dağdeviren, M. (2011). A combined approach for equipment selection: FPROMETHEE method and zero-one goal programming. Expert Systems with Applications, 38(9), 11641-11650. http://dx.doi.org/10.1016/j.eswa.2011.03.043

Zadeh, L.A. (1965). Fussy sets. Information and Control, 8, 338-353. http://dx.doi.org/10.1016/S0019-9958(65)90241-X

Zadeh, L.A. (1968). Probability measures of fuzzy events. Journal of Mathematical Analysis and Applications, 23, 421-427. http://dx.doi.org/10.1016/0022-247X(68)90078-4

Journal of Industrial Engineering and Management, 2013 (www.jiem.org)

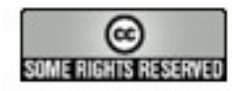

Article's contents are provided on a Attribution-Non Commercial 3.0 Creative commons license. Readers are allowed to copy, distribute and communicate article's contents, provided the author's and Journal of Industrial Engineering and Management's names are included. It must not be used for commercial purposes. To see the complete license contents, please visit http://creativecommons.org/licenses/by-nc/3.0/. 